\title{
Comparative Bioavailability of Two Oral Perampanel Formulations in Healthy Subjects: A Randomized, Open Label, Single-Dose, 2-Way Crossover Study
}

\author{
Yerino $\mathrm{GA}^{1 *}$, Feleder EC ${ }^{1}$, Otero $\mathrm{AM}^{1}$, Diaz $\mathrm{L}^{2}$, Sakson $\mathrm{M}^{2}$, Mondelo $\mathrm{N}^{2}$ and Roldán EJA ${ }^{2}$ \\ ${ }^{1}$ F.P., Clinical Pharma-Pharmacokinetic Unit, Buenos Aires, C1425BAB, Argentina \\ ${ }^{2}$ Gador S.A., Buenos Aires, C1414CUI, Argentina
}

\begin{abstract}
Background: Perampanel is a glutamate non-competitive receptor antagonist that is effective as adjunctive treatment for epilepsy. No studies regarding comparative bioavailability between a generic perampanel formulation and the brand-name product have been published in the literature. Therefore, the goal of the present investigation was to compare the bioavailability and to evaluate the bioequivalence between a novel pharmaceutical equivalent $12 \mathrm{mg}$ film-coated tablet formulation and the reference product.

Methods: An open label, randomized-sequence, two-period, two-treatment, single-dose, crossover design study in healthy volunteers $(n=24)$ was conducted. The treatment was split out by a 42 days wash-out period. The informed consent was signed by all volunteers. Healthy subjects of both genders, including non-pregnant and nonlactating females between 21-55 years with Quetelet index between $19-29 \mathrm{~kg} / \mathrm{m}^{2}$ were enrolled. Blood samples were withdrawn in vacutainers with EDTA over $168 \mathrm{~h}$ and plasma levels of perampanel were measured by HPLC/ fluorescence method. Pharmacokinetic $(P K)$ variables $\left(C_{\max }, A \cup C_{0 \text {-last }}\right.$, and $\left.A U C_{\text {inf }}\right)$ after a single oral administration dose of the test and reference treatments were analyzed by a non-compartmental PK model using natural logtransformed data and were compared by ANOVA for a two-treatment crossover design. Bioequivalence between the two formulations was evaluated using the $90 \%$ Confidence Interval $(\mathrm{Cl})$ comprised between $80-125 \%$ corresponding to the ratio of the geometric means for log-transformed PK parameters.
\end{abstract}

Results: A similar bioavailability between products was determined. Test and reference formulations showed no statistically significant differences in relation to the fixed effect of period, sequence, treatment and volunteers within sequence as random effect for $\mathrm{PK}$ variables. The estimated point and $90 \% \mathrm{Cl}$ of the ratios of $\mathrm{C}_{\text {max }}, A \cup \mathrm{C}_{0-\mathrm{last}}$ and $\mathrm{AUC}$. were $0.92(0.83-1.03), 1.04(0.98-1.10)$ and $0.98(0.86-1.11)$, respectively. The formulations showed comparable safety and tolerability.

Conclusion: The new pharmaceutical equivalent perampanel $12 \mathrm{mg}$ film-coated tablet formulation was also bioequivalent to the reference product. Therefore, both drugs are interchangeable.

Keywords: Pharmacokinetics; Bioequivalence; Perampanel; Epilepsy; Healthy subjects

\section{Introduction}

Perampanel (CAS 380917-97-5) is an Antiepileptic Drug (AED) with novel mechanism of action due to its selective, non-competitive AMPA glutamate receptor antagonist [1]. A subtype glutamate receptor, AMPA ( $\alpha$-amino-3-hydroxy-5-methyl-4-isoxazolepropionic acid) has been an active target for epilepsy drug development because it seems to participate in the induction and spread of epileptic seizures [2]. Phase III clinical trials have established the efficacy and safety of perampanel as adjunctive therapy for partial seizures with or without secondary generalized seizures in patients with epilepsy aged $\geq 12$ years old [35]. Perampanel oral film-coated tablet formulations were developed to enhance patient adherence to treatment. A hallmark of perampanel is its long half-life allowing just a one daily dose which contribute to the patient drug compliance [6]. The maximum recommended daily dose of perampanel is $12 \mathrm{mg}$ being initiated with a daily dose of 2 $\mathrm{mg}$. Since the $12 \mathrm{mg}$ film-coated tablet was not tested in clinical trials, this formulation was approved by the Food and Drug Administration (FDA) in 2012 after demonstrating bioequivalence to perampanel $2 \mathrm{mg}$ film-coated tablet formulation [7].

Several single and multi-dose Pharmacokinetics (PKs) studies have been conducted both in healthy subjects and in epilepsy patients $[6,8]$. Perampanel has a mean oral absolute bioavailability of $100 \%$ after an oral administration [9,10]. Following oral administration of a $12 \mathrm{mg}$ single dose in a subset of healthy fasted volunteers enrolled in phase I pharmacokinetic studies, perampanel showed a mean maximum concentration $\left(\mathrm{C}_{\max }\right)$ of $336 \mathrm{ng} / \mathrm{ml}$ reached at 0.5 to $4 \mathrm{~h}$ $\left(\mathrm{T}_{\max }\right)$ post-dosing with a mean area under the plasma concentrationversus-time curve $\left(\mathrm{AUC}_{\mathrm{inf}}\right)$ of approximately $21000 \mathrm{ng} \mathrm{h} / \mathrm{ml}$ and a half-life $\left(\mathrm{T}_{1 / 2}\right)$ of $100 \mathrm{~h}$ [11]. Dose-proportionally between the dose range of 0.2 to $12 \mathrm{mg}$ has been demonstrated for the AUC parameter in pharmacokinetic studies [12]. Some pharmaceutical issues should be considered in the elaboration of a new perampanel formulation. Firstly, no biopharmaceutical classification for perampanel has been established since complete dissolution is not observed at $\mathrm{pH} 4.5$ or above, being soluble in water only at acidic $\mathrm{pH}(\mathrm{pKa}=3.24)$ [11]. Also,

*Corresponding author: Yerino GA, MD, F.P. Clinical Pharma, 4484 Juncal St. 3rd Floor, Buenos Aires, C1425BAB, Argentina, Tel: 5411-47752640; E-mail: gyerino@fpclinicalpharma.com.ar

Received August 15, 2017; Accepted August 23, 2017; Published September 05, 2017

Citation: Yerino GA, Feleder EC, Otero AM, Diaz L, Sakson M, et al. (2017) Comparative Bioavailability of Two Oral Perampanel Formulations in Healthy Subjects: A Randomized, Open Label, Single-Dose, 2-Way Crossover Study. J Bioequiv Availab 9: 501-508. doi: 10.4172/jbb.1000353

Copyright: @ 2017 Yerino GA, et al. This is an open-access article distributed under the terms of the Creative Commons Attribution License, which permits unrestricted use, distribution, and reproduction in any medium, provided the original author and source are credited. 
Citation: Yerino GA, Feleder EC, Otero AM, Diaz L, Sakson M, et al. (2017) Comparative Bioavailability of Two Oral Perampanel Formulations in Healthy Subjects: A Randomized, Open Label, Single-Dose, 2-Way Crossover Study. J Bioequiv Availab 9: 501-508. doi: 10.4172/ jbb.1000353

the manufacturing process of a perampanel formulation requires the hydrate polymorphic form among the different polymorphism observed [12].

Bioequivalence between a generic and a brand-name product is currently established considering the $\mathrm{C}_{\max }$, the time to reach the maximum concentration $\left(\mathrm{T}_{\max }\right)$ and the area under a curve defined by serum concentration as a function of time (AUC) of both formulations [13]. Bioequivalence studies are important in generic versions of Narrow Therapeutic Index (NTI) drugs, such as perampanel [14]. Several generic versions of AEDs have been approved for the market worldwide in the recent years. However, published pharmacokinetic studies regarding a comparative bioavailability between a generic perampanel formulation and the brand-name product are not available in the literature.

The main aim of the present study was to compare the bioavailability in terms of rate and extent of absorption of a new generic $12 \mathrm{mg}$ filmcoated tablet formulation of perampanel manufactured in Argentina to that of the reference drug in fasted adult healthy subjects and to assess bioequivalence between both formulations. The second goal of this study was to evaluate tolerability and safety between formulations.

\section{Subjects and Methods}

\section{Study design and setting}

The study was an open label, randomized-sequence, two-period, two-treatment, single-dose, single-center, balanced, crossover trial. It was performed at FP Clinical Pharma Pharmacokinetic Unit, Buenos Aires, Argentina, during October 2016 and January 2017. The study design is summarized in Figure 1. The clinical trial protocol and the Informed Consent Form (IFC) were both approved by the Institutional Review Board, the Independent Ethic Committee (Comité de Ética en Investigación Clínica "CEIC", Buenos Aires, Argentina, revision number 1304/07/2016) and the National Regulatory Agency (ANMAT$\mathrm{MOH}$ ) before study start-up. All clinical procedures were conducted according to the ethical doctrine stated in the Declaration of Helsinki regarding clinical research, according to the ICH-Good Clinical Practice guidance, and to the FDA requirements to perform a bioavailability and bioequivalence trial $[13,15,16]$. An approved IFC was signed by each subject who participated in the study. This study is registered in Argentina-RENIS-Ministry of Health ( ${ }^{\circ}:$ IS001202)

\section{Interventions}

The study subjects were randomly assigned each group of 12 , to receive a single dose of perampanel each in one of two sequences of treatments (Test-Reference or Reference-Test) in compliance with the FDA guidance. 17 Perampanel was administered in one $12 \mathrm{mg}$ film-coated tablet as test preparation ("Pyxis", batch No. 25170), manufactured by Gador S.A. Laboratory (Buenos Aires, Argentina), or in one $12 \mathrm{mg}$ film-coated tablet of the reference drug ("Fycompa", batch No. 115072), manufactured by Eisai Pharma AG (Zurich, Switzerland) as reference preparation, either. Reference product was purchased abroad. Oral administration of treatments included $240 \mathrm{ml}$ of noncarbonated mineral water in two different dosing periods according to the predetermined randomized sequence of treatment. A 42-day wash-out period between treatments was established regarding the FDA guidance recommendation for long half-life drug studies such as perampanel [17].

Subjects were required to fast for at least $10 \mathrm{~h}$ overnight before admission to the study site and to abstain from water intake between one-hour pre-dosing and until $2 \mathrm{~h}$ after dosing. Crushing or chewing the study medication was not allowed. After each drug administration, a mouth control was carried out in all subjects. Diet restrictions also included nothing by mouth (i.e., food or drinks) during the first $2 \mathrm{~h}$ post-dose, up to $240 \mathrm{ml}$ of non-carbonated mineral intake from 2 to $4 \mathrm{~h}$ post-dose and water consumption after the $4 \mathrm{~h}$ post-dose ad libitum. All subjects received a similar lunch and afternoon meal after the 4-h and 8-h pharmacokinetic blood sample time point throughout both periods of dosing. The study medication was storage while on study according to the environmental conditions established by the prescribing information of the product provided by the sponsor. from crushing or chewing the study medication.

\section{Study population}

Sample size calculation was estimated on the formula of Marzo and Balant, considering a $\mathrm{C}_{\max }$ intra-individual coefficient of variation $(\mathrm{CV})$ of $25 \%$ for perampanel according to literature $[11,12,18]$. Twenty-eight healthy adult subjects of both genders, including non-pregnant and non-lactating females between 21 and 55 years of age were included in the study. Inclusion criteria comprised a Quetelet Index ranging from 19 to $29 \mathrm{~kg} / \mathrm{m}^{2}$. A negative serum pregnancy test (Beta-Human Chorionic Gonadotropin $[\beta \mathrm{hCG}]$ at the screening visit was mandatory in all women of childbearing potential with confirmed last menstrual period by anamnesis, except for women of non-childbearing potential (i.e. surgically sterile or with at least 2 years postmenopausal or menopause confirmed by Follicle-Stimulating Hormone [FSH] testing) with written documentation). Also, men and women of reproductive potential were compelled to agree to use a highly effective contraception method when sexually active for the time between signing of the ICF and 42 days after the last administration of study drug. Vital signs (blood pressure, heart rate and axillary temperature), laboratory tests (hematology, biochemistry, blood clots, urinalysis) and 12-lead ECGs were required to have no clinically significant findings. Screening for infectious diseases including HIV, Hepatitis B (HBV) and C (HCV) were also to be negative as a requisite. Subjects with a medical condition such as gastrointestinal disease or surgery, or cardiovascular, respiratory, hepatic, renal, hematopoietic, endocrine-metabolic, neurological or psychiatric diseases were excluded. Subjects who reported a history of alcohol or drug abuse in the last year, with QT/QTc (Bazett's Formula) interval above $450 \mathrm{~ms}$ on screening ECGs or with a history of weight gain or weight loss $\geq 10 \%$ between the screening visit and the first dose of the study drugs were also excluded. Use of medicine of any kind including herbal medicines were prohibited within two weeks previous of first dosing and up to the last sample collection. Other exclusion criteria commonly established by FDA guidance regarding bioequivalence studies were implemented at screening visit [13]. Smokers were required to abstain from of any type of tobacco while on the study. Subjects were asked to abstain from foods and beverages intake with xanthines or alcohol and to avoid sun exposure, strenuous exercise and sports for $24 \mathrm{~h}$ before the administration of the research product and during the hospitalizations at the pharmacokinetic unit.

\section{Sample collection}

Blood samples $(8 \mathrm{ml}$ each) were collected by venipuncture in vacutainers containing EDTA as an anticoagulant for pharmacokinetic evaluation at these time points: 0 (pre-dose), $0.5,1.0,1.5,2,3,5,8$, $12,24,48,72,96,120$ and 168 hours after the administration of each treatment orally. Samples were centrifuged at once and the separated plasma was stored at $-20^{\circ} \mathrm{C}$ before analysis. 
Citation: Yerino GA, Feleder EC, Otero AM, Diaz L, Sakson M, et al. (2017) Comparative Bioavailability of Two Oral Perampanel Formulations in Healthy Subjects: A Randomized, Open Label, Single-Dose, 2-Way Crossover Study. J Bioequiv Availab 9: 501-508. doi: 10.4172/ jbb.1000353

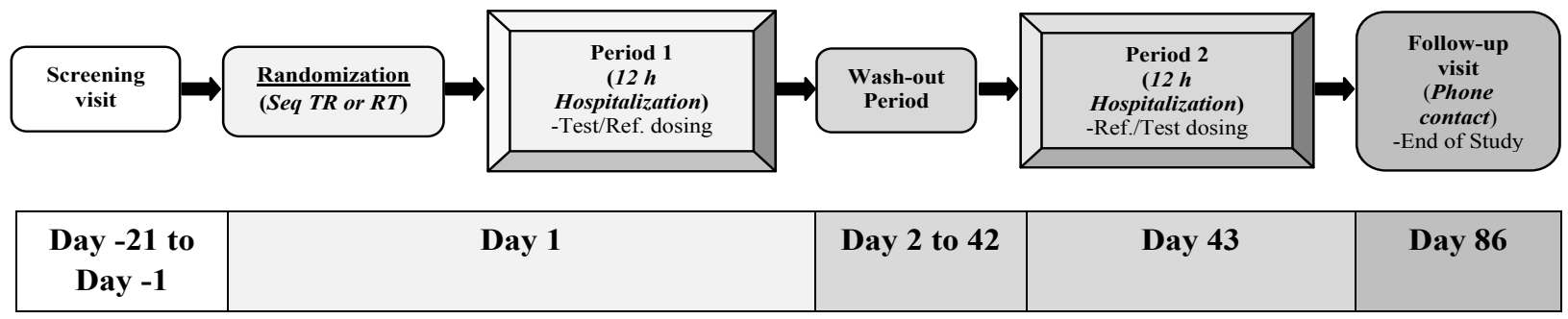

Figure 1: Study design evaluating the comparative pharmacokinetics of a single dose of two perampanel formulations in healthy subjects.

\section{Bioanalytical procedures}

Concentration of perampanel was measured using an HPLC/ fluorescence (FLD) method and a liquid chromatograph SHIMADZU Prominence 20 with an automatic injector SIL-30AC and FLD RF$20 \mathrm{~A}$ XS detector with an analytical column $25 \times 0.46 \mathrm{~cm}$, Hypersil BDS, C18, $5 \mu$, fluorescence detection within 360 to $432 \mathrm{~nm}$ in human plasma. Acetonitrile and Zink sulfate $\left(\mathrm{ZnSO}_{4} 30 \%\right)$ were used to perform the extraction method, followed, by centrifugation to separate proteins from the plasma. Subsequently, the supernatant was diluted in water and injected into an isocratic system by HPLC. The mobile phase consisted of an PRMP phase (50\%), Methanol (15\%) and Acetonitrile (35\%). Perampanel quantification was determined using the external standard method. The Lowest Limit of Quantification (LLOQ) corresponding to perampanel was $10 \mu \mathrm{g} / \mathrm{l}$. We constructed a calibration curve covering the range of 10 to $2000 \mu \mathrm{g} / \mathrm{l}$. The curves were linear over the calibration concentration range $(r=0.999)$ for each mobile phase. Three separate analytical runs, each containing 4 Quality Control (QC) levels (LLOQ, LQC: $30 \mu \mathrm{g} / \mathrm{l}$; MQC: $1000 \mu \mathrm{g} / \mathrm{l}$ and HQC: $1500 \mu \mathrm{g} / \mathrm{l})$ involving the calibration range in replicates of 5 were employed to assess the precision and accuracy of the validation assay. Inter-and intra assay precision had a coefficients of variations (CVs) $<15 \%$ and $<20 \%$ at the LLOQ. Inter-and intra assay accuracy had mean BIAS values within $\pm 15 \%$ of nominal values and within $\pm 20 \%$ at the LLOQ. The principles of the FDA guidance were considered for bioanalytical method validation [19].

\section{In vitro dissolution tests}

Dissolution studies performed in vitro of both film-coated tables were studied in a USP apparatus type II with a paddle stirrer at $75 \mathrm{rpm}$ using three dissolution mediums: $900 \mathrm{ml}$ of $0.1 \mathrm{M} \mathrm{HCL} \mathrm{(pH} \mathrm{1.2)} \mathrm{at}$ $37^{\circ} \mathrm{C}$; acetate buffer $(\mathrm{pH} 4.5)$ and phosphate buffer $(\mathrm{pH} 6.8)$ at $37^{\circ} \mathrm{C}$. An equation obtained from a standard curve was used to calculate the percentage of the released drug. Results are shown in Figure 2. A very fast dissolution profile was exhibited by both formulations at $\mathrm{pH} 1.2$ (Figure 2A). Therefore, it was not necessary to calculate f2 to demonstrate similarity at this $\mathrm{pH}$. Both formulations showed a dissolution of the pharmaceutical drug between 16 and $34 \%$ at the maximum time evaluated for 20 minutes at $\mathrm{pHs} 4.5$ and 6.8 (Figure $2 \mathrm{~B}$ and $2 \mathrm{C}$ ). Hence, the conditions to estimate $\mathrm{f} 2$ factor were not met at these pHs. However, these products can be considered with similar behavior since these results are consistent with dissolution profiles for perampanel reported previously; slightly soluble in $0.1 \mathrm{M} \mathrm{HCL}$ at 37 ${ }^{\circ} \mathrm{C}$ and practically insoluble in $\mathrm{pH} 4.5$ USP buffer acetate and $\mathrm{pH} 7.5$ phosphate buffer at $37^{\circ} \mathrm{C}[11,12]$.

\section{Pharmacokinetic evaluation}

We used a non-compartmental pharmacokinetic model (WinNonlin, version 6.4; Certara, US) to analyze plasma concentration-time data from the test and reference formulations obtained after oral dosing. The $\mathrm{C}_{\max }$ and $\mathrm{T}_{\max }$ were defined as the highest plasma concentration and the resultant sampling time, respectively. The first order rate constant linked with the terminal portion of the curve estimated by linear regression of time vs. log-concentration was considered as the slope of the log-linear regression function $(\lambda)$. The trapezoidal rule was employed to construct the area under the plasma concentration-time curve from the time of dosing to the last quantifiable concentration $\left(\mathrm{AUC}_{0 \text {-last }}\right)$. The $\mathrm{AUC}_{\text {inf }}$ was characterized as the AUC from dosing time extrapolated to infinity considering the final measurable plasma level $(\mathrm{Cn})$ and was calculated using the equation $\mathrm{AUC}_{0 \text {-inf }}=\mathrm{AUC}+(\mathrm{Cn} / \lambda)$. The elimination half-life $\left(\mathrm{T}_{1 / 2}\right)$ was calculated as $\ln 2 / \lambda$. Data from samples with pharmacokinetic values below the LLOQ in bioanalytical assays was analyzed by a generated pharmacokinetic $(\mathrm{PK})$ rule. We excluded from the $\mathrm{PK}$ analysis group any subject who experienced twice emesis at or before the median time to maximum concentration $\left(\mathrm{T}_{\max }\right)$ for the analyte [13].

\section{Safety assessment}

We performed physical examination, a 12-lead ECG, hematology, serum chemistry (fasting glucose, urea, creatinine, liver function panel, blood clots tests) and urinalysis for safety evaluation at the screening visit (Day-21 to -1). Female with childbearing potential were tested with a urine pregnancy test at screening visit and previous to each dosing period. We performed a short physical examination before each drug administration in the morning. Vital parameters (hart rate, blood pressure in supine position and axillary temperature) were recorded at the screening visit, and at predefined time-points (pre-dose, 2.0, 4.0, 8.0, and $12 \mathrm{~h}$ post-dose) during the dosing periods. Subject's Adverse Events (AEs) were collected immediately after ICFs were signed and until the end of the study. Investigators evaluated the seriousness, severity (CTCAE), and the causality assessment of AEs.

\section{Statistical analysis}

Baseline demographic variables between sequence groups (TestReference versus Reference-Test) were compared using Wilcoxon -Mann Whitney two-sample rank-sum test for mean values and Chi2 for proportions. We used natural log-transformed data to analyze the PK parameters: $\mathrm{C}_{\max }, \mathrm{AUC}_{0 \text {-last }}$ and $\mathrm{AUC}_{\text {inf }}$ for perampanel. These $\mathrm{PK}$ parameters were statistically analyzed using the ANOVA test for a 2 -treatment crossover design. The model considered the fixed effects of treatment, period, sequence and the random effect of subjects within sequence. The average perampanel bioavailability of test formulation relative to the reference formulation was expressed as the ratio of respective estimated mean exposure and $90 \%$ Confidence Intervals (CIs) in terms of $\mathrm{C}_{\mathrm{max}}, \mathrm{AUC}_{0 \text {-last }}$ and $\mathrm{AUC}_{\text {inf }}$. Schuirmann's two one-sided t tests were used to compare $\mu \mathrm{T} / \mu \mathrm{R}$ ratios for the PK parameters. Bioequivalence was demonstrated when the point 
Citation: Yerino GA, Feleder EC, Otero AM, Diaz L, Sakson M, et al. (2017) Comparative Bioavailability of Two Oral Perampanel Formulations in Healthy Subjects: A Randomized, Open Label, Single-Dose, 2-Way Crossover Study. J Bioequiv Availab 9: 501-508. doi: 10.4172/ jbb.1000353

A)

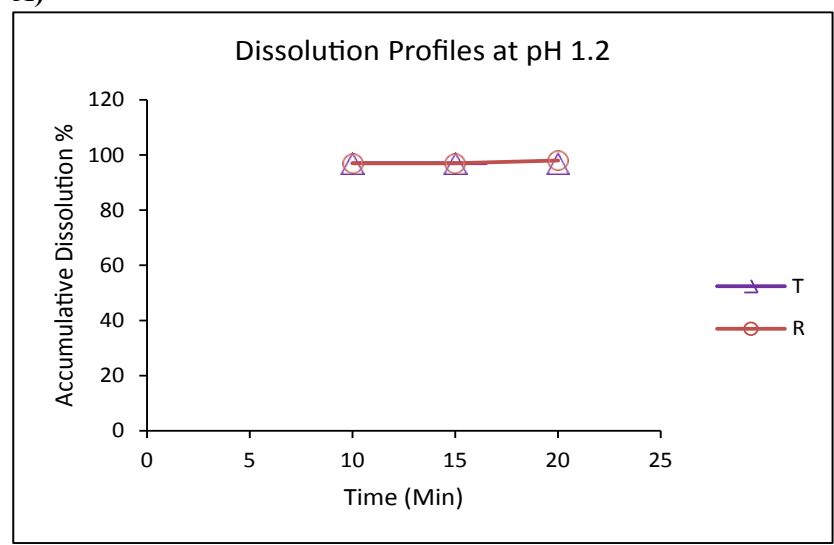

B)

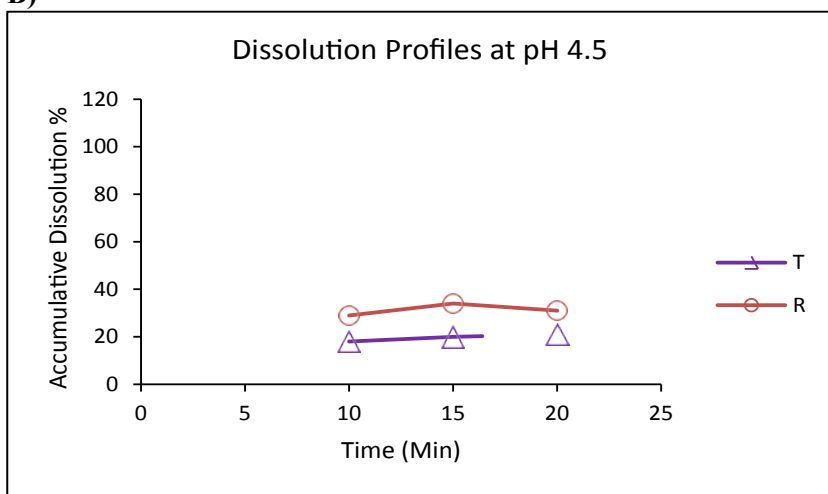

C)

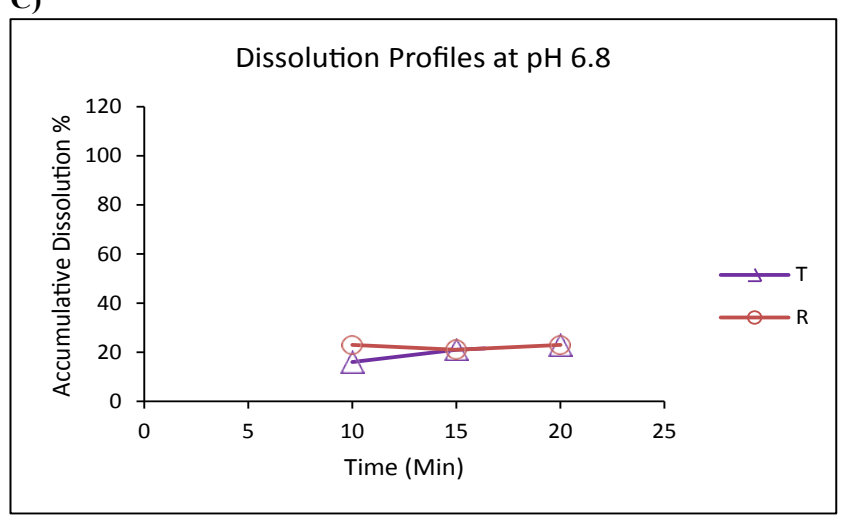

Figure 2: In vitro dissolution profiles for Perampanel for Reference (R-circles) and Test

(T-triangle) formulations.

estimate and the $90 \%$ CIs values for the ratio of the geometric leastsquares means (test treatment/reference treatment) fell within the acceptance interval of $80 \%$ to $125 \%$ for the primary PK parameters in agreement with the international guidelines for bioequivalence studies. A conventional significance level of 0.05 was used in all statistical tests $[13,20]$.

\section{Results}

\section{Subject population}

Twenty-eight healthy native Caucasian subjects participated in the trial. Four subjects withdrew their informed consent before the period 1 of the study due to personal reasons. Thus 24 subjects were randomized to the sequence group. Finally, 23 subjects completed the study according to the protocol. Subjects allocation and disposition is illustrated in Figure 3. No significant differences were found in demographic characteristics and mean heath parameters between sequence groups as depict in Table 1.

\section{Pharmacokinetics}

Twenty-two subjects comprised the data set for perampanel PK analysis. One subject was excluded for non-detectable perampanel plasma levels under the LLOQ. Plasma PK values for perampanel are described in Table 2. Mean plasma concentration-time curves from test and reference formulations after single dosing are represented in Figures $4 \mathrm{~A}$ and 4B. The two formulations curves showed a similar PK profile for an immediate release formulation with long half-life and both curves were essentially superimposed. Perampanel concentrations declined in a biphasic manner for both the test and reference formulations after the achievement of $\mathrm{C}_{\max }$. Moreover, perampanel formulations showed similar mean $\mathrm{T}_{\max }$ and half-life values. The analysis of variance using the PK parameters of $\ln \mathrm{C}_{\max }, \mathrm{AUC}_{0 \text {-last }}$ and $\mathrm{AUC}_{\text {inf }}$ demonstrated no statistically significant difference between the test and the reference formulations $(\mathrm{p}<0.05)$ regarding the fixed effect of treatment, period, sequence, and subjects within sequence as random effect.

Perampanel PK log-transformed values and the results of the statistical analysis in relation to their geometric least squares mean ratios for the test and reference treatment are summarized in Table 3. The test/ reference ratio $(\mu \mathrm{T} / \mu \mathrm{R})$ for the log-transformed data corresponding to the geometric means (\%) for all primary pharmacokinetic parameters $\left(\mathrm{AUC}_{0-\mathrm{t}}, \mathrm{AUC}_{\text {inf }}, \mathrm{C}_{\max }\right)$ and the corresponding two-sided $90 \%$ CIs were contained within the established boundaries of 80 to $125 \%$. Therefore, the null hypothesis of the two one-sided Schuirmann's $\mathrm{t}$-test was rejected $(\mathrm{p}<0.05)$. Coefficients of intra-individual variation for $\mathrm{C}_{\max }, \mathrm{AUC0}$-last and $\mathrm{AUC}_{\text {inf }}$ were $0.20,0.11$ and 0.24 ; respectively. Coefficients of inter-individual variation for $\mathrm{C}_{\max }$, AUC0-last and $\mathrm{AUC}_{\text {inf }}$ were $0.27,0.32$ and 0.47 ; respectively.

\section{Safety and tolerability}

Safety and tolerability was assessed in 24 subjects who received the investigational product. All subjects tolerated well both perampanel formulations. After a single oral dose of perampanel $12 \mathrm{mg}$ no clinically significant findings were observed relation to vital signs. AEs are summarized in Table 4. A total of 5 subjects experienced at least one $\mathrm{AE}$. The investigators considered four from five AEs as related to the investigational product. All related AEs were of mild intensity (CTCAE Grade 1) and they resolved without requiring any treatment. One $\mathrm{AE}$ (right elbow contusion secondary to local trauma) was of moderate intensity (CTCAE Grade 2) and was considered by the investigators as not related to the investigational product.

\section{Discussion and Conclusion}

The goal of this study was to compare the bioavailability in terms of rate and extent of absorption of a new pharmaceutical equivalent filmcoated tablet formulation manufactured in Argentina (test product) containing $12 \mathrm{mg}$ of perampanel to that from the reference product in native healthy volunteers; and to demonstrate bioequivalence between them. The $\mathrm{C}_{\text {max }}$ and AUC comparisons between the test and reference products showed no significance differences regarding the rate and extent of absorption. This was also evidenced by the superimposed plasma perampanel concentration-time curves. The null hypothesis that the calculated PK parameters $\left(\mathrm{C}_{\max }\right.$ and AUCs log-transformed) 
Citation: Yerino GA, Feleder EC, Otero AM, Diaz L, Sakson M, et al. (2017) Comparative Bioavailability of Two Oral Perampanel Formulations in Healthy Subjects: A Randomized, Open Label, Single-Dose, 2-Way Crossover Study. J Bioequiv Availab 9: 501-508. doi: 10.4172/ jbb.1000353

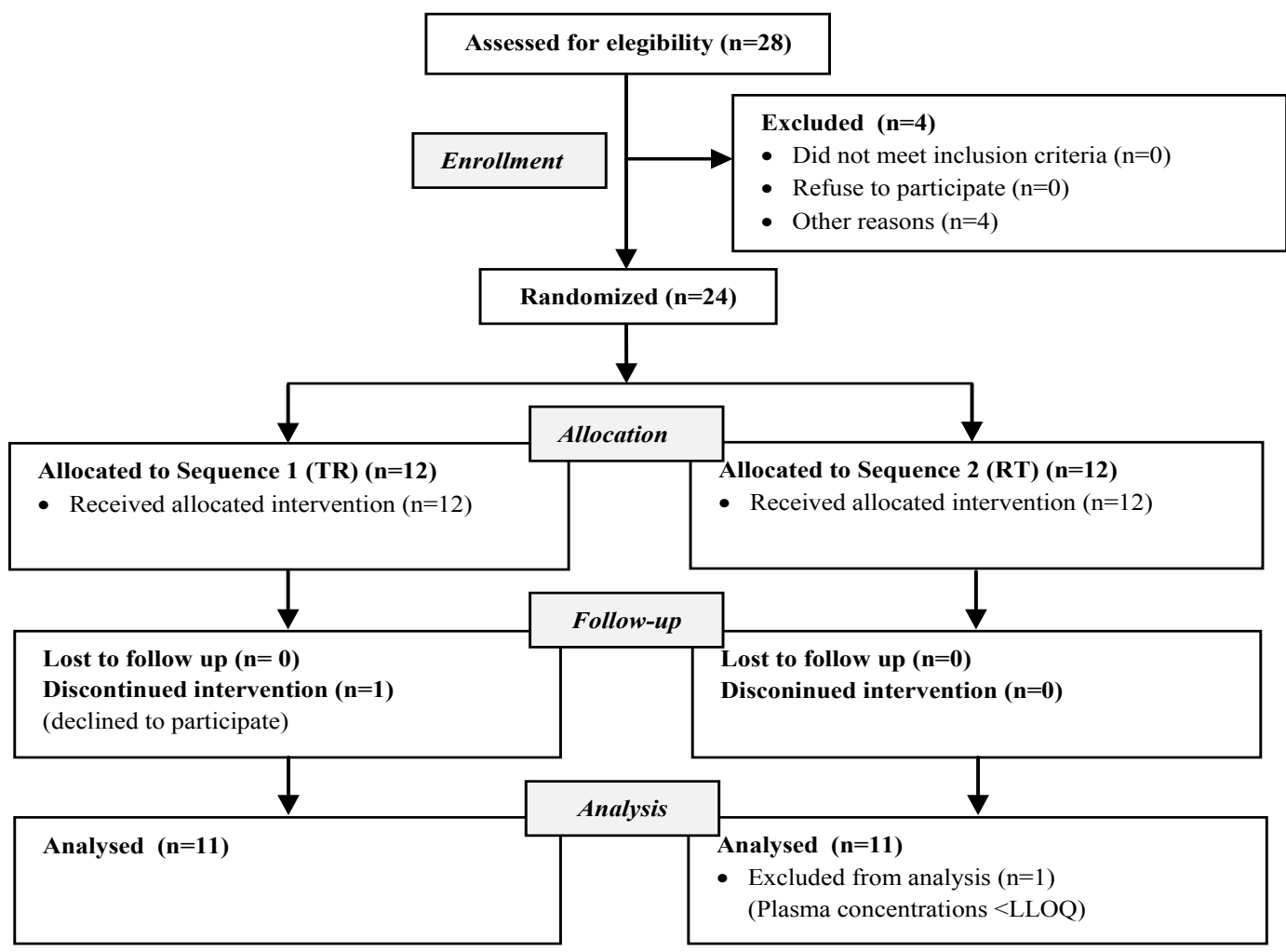

Figure 3: Study flow of subject's allocation and disposition.

\begin{tabular}{|c|c|c|c|c|}
\hline \multirow{2}{*}{$\begin{array}{l}\text { Demographic } \\
\text { Characteristics }\end{array}$} & \multicolumn{2}{|c|}{ Sequence Group } & \multirow{2}{*}{ Total $(n=24)$} & \multirow{2}{*}{$\mathbf{p}$} \\
\hline & Test-Reference $(n=12)$ & Reference-Test $(n=12)$ & & \\
\hline Age (years), mean $\pm S D$ & $35.33 \pm 12.53$ & $41.08 \pm 7.95$ & $38.20 \pm 10.68$ & 0.21 \\
\hline Height $(\mathrm{cm})$, mean $\pm \mathrm{SD}$ & $169.75 \pm 8.91$ & $170.83 \pm 9.41$ & $169.79 \pm 9.03$ & 0.60 \\
\hline Weight $(\mathrm{kg})$, mean \pm SD & $72.87 \pm 13.75$ & $76 . .90 \pm 12.35$ & $74.89 \pm 12.95$ & 0.45 \\
\hline $\mathrm{BMI}\left(\mathrm{kg} / \mathrm{m}^{2}\right)$, mean $\pm \mathrm{SD}$ & $25.38 \pm 2.98$ & $26.21 \pm 2.53$ & $25.79 \pm 2.73$ & 0.37 \\
\hline Gender (male/female), n (\%) & $8(66.6) / 4(33.3)$ & $7(58.3) / 5(41.6)$ & $15(62.5) / 9(37.5)$ & 0.67 \\
\hline Smoke (yes), n (\%) & $1(8.3)$ & $1(8.3)$ & $2(8.3)$ & 1.00 \\
\hline Alcohol (yes), n (\%) & $3(25.0)$ & $2(16.6)$ & $5(20.8)$ & 0.61 \\
\hline Xanthines (yes), n (\%) & $11(91.6)$ & $11(91.6)$ & $22(91.6)$ & 1.00 \\
\hline
\end{tabular}

Table 1: Demographic characteristics of study subjects.

\begin{tabular}{|c|c|c|}
\hline Perampanel PK Parameter & Reference Treatment $(n=22)$ & Test Treatment $(n=22)$ \\
\hline $\mathrm{C}_{\max }(\mathrm{ng} / \mathrm{ml})$, mean $\pm \mathrm{SD}$ & $197.87(55.78)$ & $189.33(85.28)$ \\
\hline $\mathrm{T}_{\max }$ (hours), mean $\pm \mathrm{SD}$ & $3.64(6.73)$ & $4.23(6.86)$ \\
\hline $\mathrm{AUC}_{0 \text {-last }}(\mathrm{ng} \mathrm{h} / \mathrm{ml})$, mean $\pm \mathrm{SD}$ & $16427.39(6636.86)$ & $17644.26(9060.38)$ \\
\hline $\mathrm{AUC}_{\mathrm{inf}}(\mathrm{ng} \mathrm{h} / \mathrm{ml})$, mean $\pm \mathrm{SD}$ & $37476.77(30964.60)$ & $35317.17(18729.91)$ \\
\hline$(\mathrm{Ke})(1 / \mathrm{h})$ & $0.005(0.003)$ & $0.006(0.004)$ \\
\hline Half-life (hours), mean (SD) & $183.82(92.72)$ & $162.37(74.26)$ \\
\hline
\end{tabular}

Table 2: Pharmacokinetic parameters of perampanel in fasting healthy subjects $(n=22)$ after a 12-mg single oral dose of test or reference treatment.

exceeded the margins of acceptance established for bioequivalence could be rejected since the $90 \%$ CIs of the ratios $(\mu \mathrm{T} / \mu \mathrm{R})$ for these $\mathrm{PK}$ parameters was revealed to be within the fixed margins $(80 \%$ to $125 \%)$ and all probability values were found at a level of statistical significance less to 0.05 by the Schuirmann's two one-sided t test procedure (probability of exceeding margins of acceptance).

To our knowledge, no other bioequivalence study evaluating perampanel as a single dosage formulation of $12 \mathrm{mg}$ between a generic and brand-name product has been previously reported in the literature. In addition, this is the first report of perampanel bioequivalence done in the same population in which the test product will be marketed.

Parameters of bioavailability observed in this study are consistent with a previous perampanel population (pop) PK analysis based on phase I studies carried out in healthy subjects using a two-compartment model with first-order absorption [6]. When perampanel is administered as a single oral dose in a $12-\mathrm{mg}$ film- 
Citation: Yerino GA, Feleder EC, Otero AM, Diaz L, Sakson M, et al. (2017) Comparative Bioavailability of Two Oral Perampanel Formulations in Healthy Subjects: A Randomized, Open Label, Single-Dose, 2-Way Crossover Study. J Bioequiv Availab 9: 501-508. doi: 10.4172/ jbb.1000353

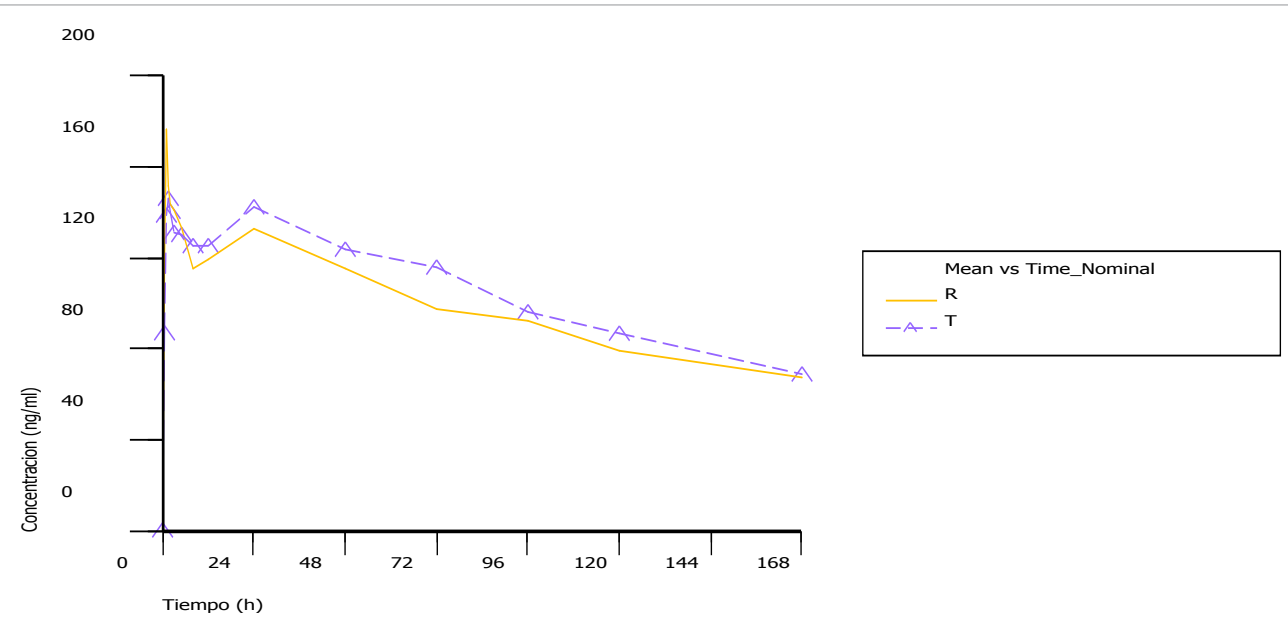

Figure 4A: Mean plasma concentration-time curves for perampanel $(n=23)$ following single dose administration of test and reference $(1 \times 12 \mathrm{mg})$ film-coated tablets, in fasting healthy subjects. Test=Triangle and reference $=$ Circles.

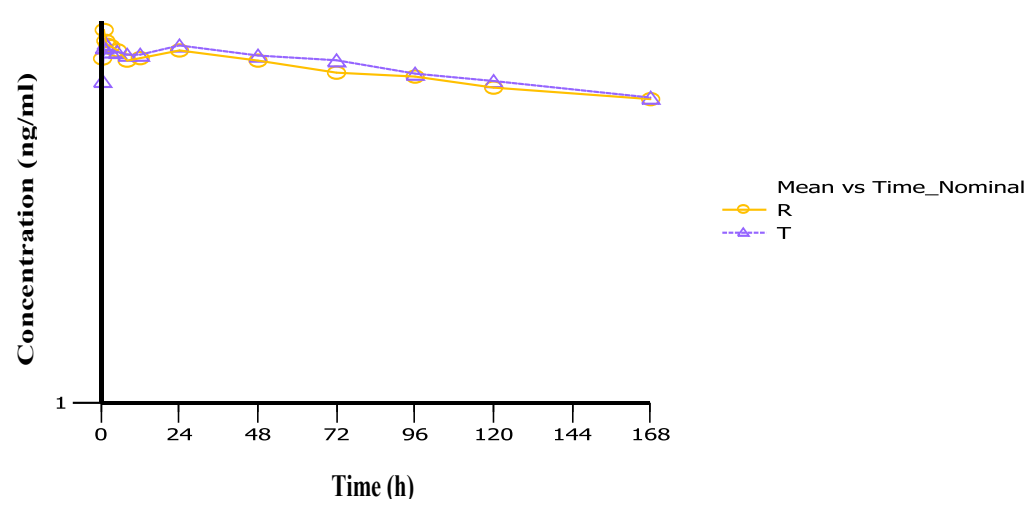

Figure 4B: Mean plasma log-concentration-time curves for perampanel $(n=23)$ following single dose administration of test and reference $(1 \times 12 \mathrm{mg})$ filmcoated tablets. Test=Triangle and reference=Circles.

\begin{tabular}{|c|c|c|c|c|c|c|c|}
\hline Pharmacokinetic Parameter & Ref GeoLMS (") & Test GeoLMS (*) & $\begin{array}{l}\text { Ratio (\% } \\
\text { Ref)) }\end{array}$ & $\begin{array}{l}\mathrm{Cl} 90 \% \\
\text { Classical }\end{array}$ & $\begin{array}{c}\text { Schuirmann's Two One-sided } \\
t \text { Test }\end{array}$ & $\mathbf{p}$ & $\begin{array}{l}\text { Power of the } \\
\text { Analysis }\end{array}$ \\
\hline $\operatorname{Ln}\left(C_{\max }\right), \mathrm{ng} / \mathrm{ml}$ & 189.57 & 175.86 & 92.77 & 83.41 to 103.17 & $\begin{array}{l}P(0<80 \%)=0.0130 \\
P(0>125 \%)=0.0000\end{array}$ & $p<0.05$ & 0.96 \\
\hline $\operatorname{Ln}\left(\mathrm{AUC}_{0 \text {-last }}\right), \mathrm{ng}^{*} \mathrm{~h} / \mathrm{ml}$ & 15481.72 & 16162.25 & 104.40 & 98.37 to 110.79 & $\begin{array}{l}P(0<80 \%)=0.0000 \\
P(0>125 \%)=0.0000\end{array}$ & $p<0.05$ & 1.00 \\
\hline $\operatorname{Ln}\left(\mathrm{AUC}_{0 \text {-inf }}\right), \mathrm{ng}{ }^{*} \mathrm{~h} / \mathrm{ml}$ & 31741.14 & 31140.74 & 98.11 & 86.59 to 111.15 & $\begin{array}{l}P(0<80 \%)=0.0053 \\
P(0>125 \%)=0.016\end{array}$ & $p<0.05$ & 0.91 \\
\hline
\end{tabular}

(*) Ref Geo LSM=Reference Geometric Least Squares Mean

(*) Test Geo LMS=Test Geometric Least Squares Mean

Table 3: Bioequivalence analysis for perampanel following single-oral dose administration of either test or reference drug (12 mg).

\begin{tabular}{|c|c|c|c|c|c|c|}
\hline \multicolumn{2}{|c|}{ Adverse Events } & \multicolumn{2}{|c|}{ Test $(n=24)$} & \multicolumn{2}{|c|}{ Reference $(n=24)$} & \multirow{2}{*}{$\begin{array}{l}\text { Total } \\
(n=24)\end{array}$} \\
\hline soc $^{*}$ & $\mathbf{P T}^{*}$ & Related & Not-Related & Related & Not-Related & \\
\hline \multirow{2}{*}{ Nervous system disorders } & Headache & $1(1)^{* *}$ & - & $1(1)$ & _ & $2(2)$ \\
\hline & Dizziness & - & _- & $1(1)$ & _- & $1(1)$ \\
\hline Gastrointestinal disorders & Nausea & $1(1)$ & _- & _- & _- & $1(1)$ \\
\hline $\begin{array}{l}\text { Injury, poisoning and } \\
\text { procedural complications }\end{array}$ & Contusion & - & $1(1)$ & - & - & $1(1)$ \\
\hline
\end{tabular}

(*) SOC: System Organ Class; PT: Preferred Term, MedDRA v 20.0

${ }^{* *}$ Number of AEs (Number of subjects with AEs) 
Citation: Yerino GA, Feleder EC, Otero AM, Diaz L, Sakson M, et al. (2017) Comparative Bioavailability of Two Oral Perampanel Formulations in Healthy Subjects: A Randomized, Open Label, Single-Dose, 2-Way Crossover Study. J Bioequiv Availab 9: 501-508. doi: 10.4172/ jbb.1000353

coated tablet formulation to healthy subjects $(n=45)$ under fasting condition, mean $\pm \mathrm{SD}$ (range) pop PK parameters corresponding to $\mathrm{C}_{\max }$ and $\mathrm{AUC}_{\text {inf }}$ are estimated in $335.7 \pm 119.8 \mathrm{ng} / \mathrm{ml}(5331-61986)$ and $21033 \pm 10034 \mathrm{ng} / \mathrm{ml}(5331-61986) \mathrm{ng} \mathrm{h} / \mathrm{ml}$, respectively [6,11]. Perampanel median (range) $\mathrm{T}_{\max }$ value calculated is 1.0 (0.5-4.0) hours $[6,11]$. In the present study, the mean calculated $\mathrm{AUC}_{\text {inf }}$ from test and reference product (35317.1 and $37476.7 \mathrm{ng}$ ' $\mathrm{h} / \mathrm{ml}$, respectively) were slightly higher and mean $\mathrm{C}_{\mathrm{mix}}$ from test and reference product $(226.8$ and $232.6 \mathrm{ng} / \mathrm{ml}$, respectively) were slightly lower than mean values reported in the previous population PK analysis [6,11]. These results may be explained due to a quite large inter-individual variability of perampanel pharmacokinetics. Perampanel's coefficients of variations (CV) expressed as CV\% in many single and multiple dose PK studies carried out in healthy subjects' range between $15 \%$ to $40 \%$ in relation to $\mathrm{C}_{\max }$ and the $\mathrm{CV} \%$ of $\mathrm{AUC}_{\text {inf }}$ is reported to vary from 30 to $60 \%$ after a single dose-dose administration [11,12]. Also, in epilepsy patients the variability of perampanel plasma concentrations is reported with an inter-individual CV of $132 \%$ [8]. In our study, the $\mathrm{AUC}_{\text {-last }}$ was not truncated after the completion of distribution phase as it was done in some previous PK studies. Therefore, differences in the duration in blood sampling collection for perampanel plasma concentrations could possibly be another source of the variability of the results in the PK parameters.

In our study, mean perampanel half-life values (162.3 and $183.8 \mathrm{~h}$ ) corresponding to the test and reference products were slightly longer than the mean elimination half-life of $105 \mathrm{~h}$ estimated in the pop PK analysis from phase I studies $[6,9,10]$. A broad variation in Perampanel's half-lives values is also reported in literature being proposed that the difficulty to estimate if there are two or three disposition phases could possibly be linked to the different terminal half-life results $[6,11]$. In the present study, half-life between-subject CV for the test and reference formulation were $45.70 \%$ and $50.4 \%$, respectively. Since there is no study reported in individuals of the Latin American region, the variability could also be a partially explained as a population effect.

The pharmacokinetics of perampanel in epilepsy patients has been reported to be like that in healthy subjects $[11,12]$. An important therapeutic advantage of perampanel is its long half-life which leads to a longer time to attain the steady state considering that lees amount of drug is eliminated between doses allowing longer dosing intervals. This PK behavior might lead to an improvement in the patient medication compliance.

In a pooled $\mathrm{PK} / \mathrm{PD}$ analysis for phase III trials, the probability of AEs, such as, dizziness, somnolence, fatigue, irritability, gait disturbance, weight increase, dysarthria, euphoric mood and nausea correlated well the increasing plasma concentrations of perampanel [11]. In our study, only four AEs: headache (2), nausea and dizziness, all mild intensity (CTCAE Grade 1) related to the investigational product were registered. No serious or unexpected AEs were identified.

It has been considered that epilepsy patients may be at higher risk of seizures when they are switched from brand-name to generic AEDs in literature $[21,22]$. However, a systematic review and meta-analysis of trials comparing seizure outcomes from brand-name and generic AEDs showed no association between loss of seizure control and generic substitution for at least three types of AEDs [12].

In conclusion, this study demonstrated that both formulations were comparable in terms of rate and extent of absorption. The study also illustrated that the point estimate of $90 \%$ CI for the logtransformed $\mathrm{C}_{\text {max }}, \mathrm{AUC}_{0 \text {-last }}$ and $\mathrm{AUC}_{\text {inf }}$ were in the margins of 80 to
$125 \%$ and that no significant difference was found in the analysis of variance for these log-transformed PK parameters. Therefore, the present study demonstrated that the new pharmaceutical equivalent perampanel $12 \mathrm{mg}$ film-coated tablet formulation is bioequivalent to the reference product. In this context, both formulations can be considered therapeutically equivalent and interchangeable as well.

\section{Acknowledgments}

All authors have approved the final article. All authors are grateful to Dr. Carlos Feleder, FP Clinical Pharma for providing editorial support.

\section{References}

1. Hanada T, Hashizume Y, Tokuhara N, Takenaka O, Kohmura N, et al. (2011) Perampanel: a novel, orally active, non competitive AMPA-receptor antagonist that reduces seizure activity in rodent models of epilepsy. Epilepsia 52: 13311340.

2. Rogawski MA (2011) Revisiting AMPA receptors as an antiepileptic drug target Epilepsy Curr 11: 56-63.

3. French JA, Krauss GL, Biton V, Squillacote D, Yang H, et al. (2012) Adjunctive perampanel for refractory partial-onset seizures: randomized phase III study 304. Neurology 79: 589-596.

4. French JA, Krauss GL, Steinhoff BJ, Squillacote D, Yang H, et al. (2013) Evaluation of adjunctive perampanel in patients with refractory partial-onset seizures: results of randomized global phase III study 305. Epilepsia 54: 117125.

5. Krauss GL, Serratosa JM, Villanueva V, Endziniene M, Hong Z, et al. (2012) Randomized phase III study 306: adjunctive perampanel for refractory partialonset seizures. Neurology 78: 1408-1415.

6. Patsalos PN (2015) The clinical pharmacology profile of the new antiepileptic drug perampanel: A normal noncompetitive AMPA receptor antagonist Epilepsia 56: 12-27.

7. NDA Approval (2001) Act for FYCOMPA (perampanel) Tablets 2 mg, 4 mg, 6 $\mathrm{mg}, 8 \mathrm{mg}, 10 \mathrm{mg}, 12 \mathrm{mg}$. Department of Health and Human Services. Food and Drug Administration.

8. Gidal B, Majid O, Ferry J, Hussein Z, Yang H, et al. (2014) The practical impact of altered dosing on perampanel plasma concentrations: pharmacokinetic modeling from clinical studies. Epilepsy Behav 35: 6-12.

9. Fycompa USPI (2016) Perampanel (Fycompa) US prescribing information

10. Fycompa SPC (2016) Perampanel (Fycompa) Summary of product characteristics.

11. Perampanel Clinical Pharmacology Review (2012) US Food and Drug Administration FDA.

12. Perampanel (Fycompa) Assessment Report (2012) European Medicines Agency (EMA). (EMA/424476).

13. U.S. Department of Health and Human Services, Food and drug Administration Center for Drug Evaluation and Research (CDER) (2003) Guidance for Industry: Bioavailability and Bioequivalence Studies for orally Administered Drug Products - General Considerations. Revision 1. Rockville, MD, USA.

14. Kesselheim AS, Stedman MR, Bubrick EJ, Kesselheim AS, Stedman MR, et al. (2010) Seizure outcomes following use of generic vs. brand-name antiepileptic drugs: a systematic review and meta-analysis. Drugs 70: 605-621.

15. World Medical Association Declaration of Helsinki (2013) Ethical Principles for Medical Research Involving Human Subjects. Fortaleza, Brazil.

16. CDER (1996) U.S. Department of Health and Human Services, Food and Drug Administration Center for Drug Evaluation and Research (CDER). ICH E6. Good Clinical Practices: Consolidated Guidance.

17. Food and Drug Administration (2014) Draft guidance on Perampanel.

18. Marzo AL, Balant LP (1995) Bioquivalence: an updated reappraisal addressed to applications of interchangeable multi-source pharmaceutical products. Arzneim-Forsch/Drug Res 45: 109-115.

19. CDER (2001) U.S. Department of Health and Human Services, Food and drug Administration Center for Drug Evaluation and Research (CDER). Guidance for Industry: Bioanalytical Method Validation. 
Citation: Yerino GA, Feleder EC, Otero AM, Diaz L, Sakson M, et al. (2017) Comparative Bioavailability of Two Oral Perampanel Formulations in Healthy Subjects: A Randomized, Open Label, Single-Dose, 2-Way Crossover Study. J Bioequiv Availab 9: 501-508. doi: 10.4172/ jbb.1000353

20. European Agency for the Evaluation of Medicinal Products (2001) Committee for Propietary Medicinal Products (CPMP). Note for Guidance on the Investigation of Bioavailability and Bioequivalence. CPMP/EWP/QWP/1401/98. London, UK.

21. Hussein Z, Critchley D, Ferry J (2011) Population pharmacokinetics of perampanel, a selective, non-competitve AMPA receptor antagonist, in patients with refractory partial-onset seizures participating in a randomized, doubleblind, placebo-controlled phase III study. Epilepsia 52: 248-249.

22. Jobst BC, Holmes GL (2004) Prescribing antiepileptic drugs: should patients be switched on the basis of cost? CNS Drugs 18: 617-628. 